\title{
What causes Large Price Changes? Financial Engineering Perspective
}

\section{Pooja Bhattacharya*}

Institute of Mathematics and Application, Bhubaneswar, Odisa, India

\begin{abstract}
As if characterless, the stock market prices behave atypically. They cause loss and profits and because all regulatory measures. In-spite of more than a century of mental-storming large price changes is noted having idiopathic genesis. And, large price changes normally mean profit. The cause (large price changes) have been studies and 'gaps' have been identified in the case of the London Stock Exchange (LSE). In large exchanges 'market order' and 'limit orders' are ever present resulting in 'gaps'. Gaps=robust trading=more employment=better economy. This transaction provides a nascent (numerical) and 1st time original attempt as to how to engineer 'gaps'.
\end{abstract}

\section{Introduction}

Stock exchanges are a house of complex variety e.g., London Stock Exchange [1]. Stock Exchange and more pertinently Large Stock Exchanges (LSE) are considered as the heart (pumping centre) in the money-merchandise maze that wraps the globe, irrespective of time or latitude zones. Stock exchanges deal with company holding (financial ownership) through 'equities' (various types of shares). Large changes in equity prices are known as large price changes. These are swings. Such swings have pan global effect and also have acute effect on national economies and on youth employment efforts. Our aim is to set before the reader a pioneering/first time numerical model based efforts - so as to forecast what cause large prices change, what the end result is and how to best utilize for maximizing prosperity. Markets and Finance means and involve money and mounds which all have numerical values as per standards. Equities being of various types run into millions per company. In a LSE (say London or New York) the numbers sum up to few billions; with world wide spread and values running into trillions. And, one LSE is grossly insufficient on one hand, while more than one make the number game and more complex. The share value depends on the robustness of any company at any given point of time, thus every aspect is fluid. The trading domain of shares is referred to as market. Thus the market is always in flux. Markets/ Commerce is marked by Radom events which can also be averred as misbehaviour [2], as in classrooms or fish markets. The fun is that that there is joy in applying mathematics.

A volume/mound of shares are known as 'stocks', which can be reduced and or enlarged or held as fixed in vary many ways in a nonstop manner to facilitate sale and purchase of the shares that make the stocks and or because of overpowering external stimulus. This is Stochastic - as good as natural phenomena. It denotes very large, very diffused, numerous means, methods and points of (energylcash capital) induction and or deductions and or decay. Therefore, alpha numerical tools are necessary to translate the various and or all aspects of such mechanics into black and white (not possible alphabetically). Since markets dominate and determine our times and life such analytical methods has emerged as a niche specialization [3]. We hope to be one (some day).

\section{Literature Review (Thematic)}

Since Bhaskarachaya's time i.e., c.500 A.D., [4] or even earlier [5] the alpha numeric have been used as integers (in this part of the world) to explain time and space i.e., very large and complex natural phenomena [6]. Time and Space also forms the perimeters of markets (commerce), while cash, credit, mind, kind, kindness, calamity, greed and need (etc.) provide the kinetics. Which all together get to be known as commercial stochastic (complex)? Kiyoshi Ito, the eminent (Japanese) mathematician used integers to explain stochastic aspects [7]. It was foundation work. Calculus is a method used in the mathematical study of random events including stochastic processes. It too uses integers and is applied in various fields, and when done so in commerce and or in state planning it gets to be known as mathematical finance [8]. Calculus was used by Nobel Laureate economist Prof. Robert C Merton (1973) to explain needs, behavior and pricing of shares $\backslash$ crisps and especially of merchandise. The term 'mathematics' (as in mathematical finance) was more used by Sir J M Keynes (UK, c.1887-1982) in a deriding manner in relation to Alfred Marshall (USA, c.1842-1924). Merton preferred the term Quantitative Finance [9], in tune with the American style of moving away from classical phonetics. Mathematical $\backslash$ Quantitative Finance methodologies can be used for discussing the mechanics of modern market, initial public offering of shares; and or in bringing out the symmetry in fiscal matters (vix., trade statements; policy); may start and end with abstract numbers to validate the usability of known mathematical formula or lattices thereof. Quantitative finance may relate more to (another perspective, with a shift in view point) how much (quanta) of money (i.e., energy) may be needed for attaining certain work done levels; what and how much be and can be mobilized and how; from where and whence, and what shall then remain out and or undone. The difference if any between Mathematical and Quantitative $(f)$ is difficult to discern. Either are style statements. Assists yeomanly in 'analyses and also 'speculation'. Financial Analysis is post event (numerical) inquest, while speculation in (numerical) hypothesis. It helps in presetting of objective(s). French mathematical genius and prodigy have given to us the concept of 'mathematical speculation' [10], which has teleconnection with 'Probability Theory' [11]. Markets are the very place of speculations and probabilities, which in turn has its umbilical's in statistics. And, in India Mathematics, Statistics and Commerce as a

*Corresponding author: Pooja Bhattacharya, Institute of Mathematics and Application, Bhubaneswar, Odisa, India, Tel: 0674-2386972; E-mail: pooja.bhattacharya11@gmail.com

Received June 21, 2017; Accepted January 18, 2018; Published January 25 2018

Citation: Bhattacharya P (2018) What causes Large Price Changes? Financial Engineering Perspective. Int J Account Res 6: 172. doi:10.4172/2472114X.1000172

Copyright: $\odot 2017$ Bhattacharya P. This is an open-access article distributed unde the terms of the Creative Commons Attribution License, which permits unrestricted use, distribution, and reproduction in any medium, provided the original author and source are credited. 
comprehensive combined subject is given importance in the syllabus [12]. Hence, rudimentary mathematics is already being emphasized by the academia in India. Therefore, pure and higher mathematical tools and devices can be used to conduct 'financial engineering' [13]. Thus, (under teacher's guidance) a student of financial engineering can do 'speculation' (gaming), with ease and elan, which is vital in commerce. In this communication we shall attempt speculation. Indeed use numerical routes that non pre to us have attempted with.

Large price changes may be driven by a variety of Reasons [14-16]. Large price changes are events recorded and reported from the stock exchanges [17]. Farmer et al. [18] have (possibly for the first time, i.e., pioneering work which is why we start from them) used the shop floor of the LSE as their candidate platform and raise the question 'what causes large fluctuations in the price of a crisp'. To do this, Farmer et al, use quadratic equations of the $1^{\text {st }}$ order and come to the conclusion that it is the gap between 2 tranches of the supply of any given merchandise/ crisp that causes large fluctuations. They use individual items and its trading events to demonstrate their theory. The study also brings out co-linearly that granularity and liquidity are also aspects. Granularity denotes size reduction i.e., 'fine grained' of the tradable item to the least and also best possible size/value, etc., e.g., shares (theory of preferred size come into play). Liquidity means high level of trading activity of the said grains i.e., buy and sell without affecting the price of that grain asset. In a stock exchange as large as the LSE 'market order' and 'limit orders' are ever present (constant phenomena) - filled price levels. They mean that the combinations of granularity+liquidity are two sides of the process which manifests together and yet not unitedly (for every item/event). These are independent processes and are non-linear and thus lead to fluctuations in liquidity. These aspects can well be also appreciated using numbers. We make a nascent effort [19].

\section{Objectives and Significance of the Study}

Moreover, when supply side is robust it leads to large sales sans any deviation effect on the price. However, there is limit to which the agents will release stocks and these leads to gaps which in turn because large rises'. In other words stocks are there, being held in the books, not being released, resulting in gaps and consequent large price changes. This means prices can effectively be raised by engineering gaps (e.g., hoarding of stocks). This also means that all the agents will be trying such methods from across the world/across time and lat zones and hence it will be quite difficult to engineer gaps intrinsically. And we also know that agents split their wares and do not off load at a time, so also do they split their orders over a wider spectrum of the price/item. This inflicts obstinacy in the liquidity characterlbehavior. Logically such a stock/group will be also a daily-well traded member. The bidders will ensure that gaps do not occur (even via cancellation), try how much the askers may strive. Gaps then have to be patronized by extraneous events/externally. There are no alternatives. Thus our objective is to attempt a (though nascent) pioneering numerical model so as to enable a forecast in real time (stock exchange floor) what cause large price change, what is the end result and how to best utilize for maximizing prosperity. In its present form this manuscript (which is crude study based crass paper) apparently has small significance, nevertheless has an original place and position based significance (as non pre to us have ever attempted anything alike), which shall widen by and by under guidance. The Objective and the Significance are synergic and form a couple (symbiotic). Nearly 80 percent of all Fortune 500 companies have been doing their core business through the Internet. This type is on the rise by leaps and bounds in India (1.2 Billion Stomachs) and China (1.6 Billion stomachs). Every $6 \mathrm{~h}$ the stomach is hungry, every $24-48^{\text {th }}$ hour the mind of the well fed seeks a change. Home delivery (including LPG subsidy) is the buzz word (even in Govt., corridors). Home deliver includes pen-to-pensions. It translates as e. commerce and comes with speed and never before demand on logistics and smart maneuvers. Every aspect is associated with large numbers and software based control (non gumasta). Therefore, there is an unputdownabale forward looking Significance (national and societal) in/to our Objective(s).

\section{Methodology: Numerical Model}

We have been working towards such goal and have been compiling our findings, models and methods [19]. This communication arises thereof. Technically and de-facto 'gaps' here connotes and denotes the difference between the quantum of the market orders: quantum of the bids at moment $m$. There is a time factor embedded (which the respected and learned authors seem not to have spoken about)... This is important vis-à-vis any consideration for 'large returns' and sustained large returns (Bullish).

If $m o: b$ is not 1 (at any tradable window of time $T t$ ) then there will be discreet fluctuations $d f$.

When $d f$ be of the order $\mathrm{x}^{-1}$ prices may stall or even go down (over $T t)=$ Bearish.

When $d f$ be of the order $\mathrm{x}^{+1}$ prices will then go up $\mathrm{x}^{+2,3 \ldots}$ then gaps will start getting obstinate ...Tt will also widen/keep widening. Tt will itself become another variable of reckon. Resulting in windfall gains and trade floor joy.

Taking cue from the lovely caption we then raise the question 'at what point of time will the agent/group having a large stock opt for gap widening i.e., engineer a wider gap?'

We look into mother nature's processes and make a conjecture as follows:

If a crisp has a feature as alike mo: $b=1$ and if it (also) thus stands positively poised for $0.6 \mathrm{Tt}$ period it then is likely to progress into the domain of $\mathrm{x}^{+1}$ and onward. Here the average Tt unit is defined as 1 and a ratio of 1:1.6 is a Fibonacci couple [20] i.e., the ancient Vrihanka Pingal as in Sanskrit (Sanatan Ganita)-this is a hypothesis, because such couples are firm/reliable. Tt firmness is essential. Tt infirmity faults gaps. Gap-lessness is deleterious for the whole financial systems \& employment (a well-known feature of recession; India 2006-12). So, in our view 'gaps' are important members of the financial markets.

\section{Discussion}

(Humbly said) We also find that the learned and respected authors have used the term 'microscopic' (as has been used also by the respected scholars from Cornel Uni., USA, in 2002. We think the desire is to tell the readers that their study is based on micro units and at micro level with universal implication(s). The phone microscopic is then a malapropos. Nevertheless, the paper opens lovely new vistas.

As students of financial engineering we find the caption very profitable and being loaded with opportunities e.g., we can attempt organize gaps. 'How to Create Gaps". Gaps generate employment.

\section{Findings and Conclusion}

We note that in financial market the theory of 'preferred size' can be applied in an altered manner. If a product is fine grained it will then tend to thwart efforts of gap engineering. A fine grained product that has a wide range in size $\&$ value and power alias diversely 
fractaled (kutaka) i.e., non-Seriprinsky's type fractionation [20] i.e., asymmetrically granulated stocks will offer better scope to the Finengineer for intermittent gap creation in a never die manner. We can think of a 'pass \fail' test i.e., Sieve Test.

Sieve test for us means a non-symmetrically granulated stock that also has (uniform) high liquidity. Such stocks will logically be the best target candidates for engineering of gaps, on-\&-often.

To maximize applied relevance of this paper we can (attempt) identify which stock is likely to suffer the widest gap; which will bring the maximum return; which will retain frequency, etc. In new ways.

As far as the caption is concerned, we are of the considered opinion that such Gap theory (locating the gaps in stock books) can also be graphically demonstrated via cartographic route (software aided) by using horizontal bar diagram (alike graphic equalizerlanimation). The gaps will automatically coincide in relation to $T t$ as the stimulating question's part (signal). It will be a much simple, more accurate, versatile, and a real time tool for shop floor visualization and instant decision making.

From the above deductions it is clear that there is a rationale behind large price changes in the stock market(s) and that it cannot be paraphrased as 'characterless'. At best it is mischief monger, which when handled deftly evolves and devolves as prosperity. And such rationale is a complex summation of numerous factors specially being hard counted stocks and the soft countable psychosomatic aspect of the human mind. Therefore, it is somewhat alike hormone caused mood changes as in women, which offers lot much opportunity and scope for study. To our mind non pre to us have made any such type of numerical attempts that may have also applied value via computer software programming (real time applied benefit).

\section{Acknowledgement}

Respected Faculty specially Dr. Sashmita mishra \& Director Prof. Padhi (both of Institute of Mathematics and Applications) \& Dr. Deepak Bhattacharya 25-22014 \& again Sep-2016.

\section{References}

1. www.londonstockexchange.com/

2. Mandelbrot, Benoit, Hudson, Richard L (2014) the Misbehaviour of Markets: A Fractal View of Financial Turbulence, Basic Books.
3. Tanya S. Beder, Cara M, Marshall (2011) Financial Engineering: The Evolution of a Profession, Wiley.

4. Bhaskaracharya-II, Aryabhatiyam (2008) Odisa State Museum-iron stylus engraved (hoary) Palm Leaf Manuscript No. G.1. Indian Journal of Histology of Science. Indian National Science Academy 43: 101-108.

5. Mukherjee Jayabrata, Deepak Bhattacharya (2016) Computation (Abacus) Aspects of the Sahasralingam. International Journal of Computer Applications Foundation of Computer Science 143: 13-20.

6. Bhattacharya Deepak (2016) Is Hindu Astro-Mathematical Traditions Traceable in Indo Archaeology? Advanced Science Letters 22: 319-326.

7. Kiyoshi Ito (1944) Stochastic Integral, Proceedings of the Imperial Academy 20: $519-524$

8. Jean-Michel C, Yuri K, Bernard B, Pierre C, Isabelle L, et al. (2000) Louis Bachelier on the Centenary of Theories de la Speculation. Mathematical Finance 10: 341-353.

9. Merton, Robert C (1973) Theory of Rational Option Pricing, Bell Journal of Economics and Management Science. The RAND Corporation 4: 141-183.

10. Louis Bachelier, Théorie de la (1900) speculation Paris.

11. Laplace, Komte ML (1812) Theory Analytic Des Probabilities, MV Courcier Imperial Library for Mathematics, Paris.

12. Maharashtra State Board of Secondary and Higher Secondary Education (2016) Mathematics \& Statistics: Commerce, for Std XI 2: 2nd Ed, Targe Publication, Pune.

13. Suresh G, Joshua L, Pavel G, Chen Zhao (2013) Large Price Changes and Subsequent Returns 1-43.

14. Razvan Stefanescu, Ramona Dumitriu (2016) Contrarian and Momentum Profits During Periods of High Trading Volume Preceded by Stock Prices Shock International Conference, "Risk in Contemporary Economy".

15. Officer RR (1972) Distribution of Stock Returns, Journal of American Statistica Association 67: 807-812.

16. Fama EF (1965) the behaviour of stock-market prices Journal of Business 38 : 34-105.

17. Doyne Farmer J, Laszlo G, Fabrizio L, Szabolcs M, Anindya S (2004) what really causes large price changes? Quantitative Finance 4: 383-397.

18. Bhattacharya Pooja (2014) Preparatory Dataset

19. Rath SK, Naik PC (2005) Fibonacci Structure in Conch Shell, Current Science 88: 555-557

20. Bhattacharya Pooja, Swastika Bhattacharya (2009) Orissan Design Inspired Systems \& Aero vehicles [Odisa]: A Concept, NASA space Launch Vehicle Design Contest. 